\title{
THE TEACHING PROCESS IN THE PANDEMIC DISEASE SITUATION AND THE PROGRESS OF THE TEACHING IN DISTANCE
}

\author{
PËRPARIME HYSNI ZEKA \\ University "Aleksander Xhuvani, Elbasani, Albania "Deparment \\ of Letters and Teaching School, Albania
}

\begin{abstract}
Science teaching is a complex activity that lies at the heart of the vision of science education presented in the Standards. The teaching standards provide criteria for making judgments about progress toward the vision; they describe what teachers of science at all grade levels should understand and be able to do. There is much (potentially) to be excited about here. Few would argue against having greater access to more learning opportunities, especially when those opportunities are offered for "free", where there is latent unmet demand, and where the opportunities themselves are well constructed and offer real value for learners.
\end{abstract}

To highlight the importance of teachers in science education, these standards are presented first. However, to attain the vision of science education described in the Standards, change is needed in the entire system. Teachers are central to education, but they must not be placed in the position of being solely responsible for reform. Teachers will need to work within a collegial, organizational, and policy context that is supportive of good science teaching. In addition, students must accept and share responsibility for their own learning.

Education system in pandemic disease

As rising incomes and affordable air travel continue to hasten the movement of hundreds of millions of people (and viruses) around the world more quickly than ever before, we will most likely see many more future outbreaks of disease that threaten and disruptive normal life. Students and education systems will unfortunately be on the front line of many such outbreaks, and it is in such circumstances that the usefulness, and potential transformative power, of ICTs in the teaching and learning process will perhaps be put to their real test.

If such a public health event causes the large-scale closure of schools Student-teacher interaction that is based merely on academic progress or behavior management creates inhibitions within a student and stifles true relationship-building. Those teachers that show respect towards their students and a keenness to help them through their difficulties become the object of respect themselves and trigger a drive among students to learn and make their teachers proud.

Key words: Pandemic disease situation, Teaching in distance, Class communication, Albanian language, education directories, teacher training, school documentation,

JEL Classification System: SI, S2, S3, N0, N1, N2, N3 


\section{GENERAL INFORMATION AND PURPOSE OF THIS PAPER RESEARCH:}

All school staff and complete educational system should be alerted to dangers of infections if that has happened. It is important to remember that any person could potentially have disease-carrying organisms, even if they have no signs or symptoms of illness. Full responsibility for developing recommendations to assist school policymakers to establish reasonable and practical guidelines for school personnel, when working with children who have infectious diseases is on local community, educational system and whole country. The most important tool that school management should use is a comprehensive plan before an outbreak of disease. In some instances, school staff should be informed of the enrollment of a student who is known to have a chronic infectious disease.

There remains a risk that some students who are or will be enrolled in school are unknown carriers of infectious diseases. It is strongly recommended that school authorities establish policies and procedures to reduce the risk of spreading disease, regardless of the presence or absence of a student known to have an infectious disease. All teachers know that planning is a critical component of effective teaching.

One important aspect of planning is setting goals. In the vision of science education described in the Standards, teachers of science take responsibility for setting yearlong and short-term goals; in doing so, they adapt school and district program goals, as well as state and national goals, to the experiences and interests of their students individually and as a group. Source: Teacher standard and performance 2007

At the level of higher education, however, we perhaps shouldn't be too surprised if these new opportunities at the high school level are first seized upon, by some of the groups with the greatest learning needs for example, students in overcrowded, poorly resourced secondary schools in developing countries, or even students who would like a secondary education, but for a variety of reasons aren't able to receive one but rather by those best placed to take advantage of them.

Once teachers have devised a framework of goals, plans remain flexible. Decisions are visited and revisited in the light of experience. Teaching for understanding requires responsiveness to students, so activities and strategies are continuously adapted and refined to address topics arising from student inquiries and experiences, as well as school, community, and national events. Teachers also change their plans based on the assessment and analysis of student achievement and the prior knowledge and beliefs students have demonstrated. Source: Teacher standard and performance 2007

Thus, an inquiry might be extended because it sparks the interest of students, an activity might be added because a particular concept has not been understood, or more group work might be incorporated into the plan to encourage communication. A challenge to teachers of science is to balance and integrate immediate needs with the intentions of the yearlong framework of goals.

The standards for science teaching are grounded in five assumptions.

1. The vision of science education described by the Standards requires changes throughout the entire system.

2. What students learn is greatly influenced by how they are taught.

3. The actions of teachers are deeply influenced by their perceptions of science as an enterprise and as a subject to be taught and learned.

4. Student understanding is actively constructed through individual and social processes.

5. Actions of teachers are deeply influenced by their understanding of and relationships with students. 
Learning with new technologies has of course been around for many decades but, broadly speaking, has not (yet) had the 'transformational' impact that has long been promised. "Gradually, then suddenly" is how one of Ernest Hemingway's characters famously describes how he went bankrupt.

Might this be how the large-scale adoption of educational technologies will eventually happen as well in much of the world?

Can we do anything with technology to help our students while our schools are closed?', and so I thought it might be useful to revisit, and update, that earlier post, in case doing so might be a useful contribution to a number of related discussions are occurring.

Solely improving students' relationships with their teachers will not produce gains in achievement. However, those students who have close, positive and supportive relationships with their teachers will attain higher levels of achievement than those students with more conflict in their relationships. Positive teacher-student relationships draw students into the process of learning and promote their desire to learn.

(assuming that the content material of the class is engaging, age-appropriate and well matched to the student's skills). Source: Science Teaching Standards 2008

\section{HYPOTHESES AND THE AIM OF THIS PAPER RESEARCH}

At the school and community level1, in the case of as extended families grow larger, less income is earned, and ever fewer resources must be spent to support more people and to pay for expenses related to illness and death, less money will be contributed by the community to the school. At the system level, less money may be available to the education system both absolutely (due to a shrink-age of the national product and government budget) and relatively (due to stronger claims made on the budget from other sectors). Many school management teams, that is, principals, deputy principals and heads of departments are facing major managerial and administrative problems of handling and dealing with the emergency situation.

Strong teacher-student relationships can even act as a buffer against the potentially adverse effects that insecure parent-child attachment can have on students' academic achievement (O'Connor \& McCartney, 2007). Applied to the classroom environment, teachers play a critical role as live models from which students can learn social behaviors and positive communication skills. Social cognitive theory also sheds light on the importance of feedback and encouragement from teachers in relation to student performance. Teachers serve as role models and help regulate student behavior through interactions and relationships.

This video clip shows a 16-year-old boy describing one way his teacher is modeling behavior. Given the relationship he describes, it is easy to see the influence that this teacher has on the student.

1 Professor of Professional Studies Dalibor Kekić, PhDAssistantProfessor Slobodan Miladinović, PhDAcademy of Criminalityand Police Studies, Belgrade 
ISSN 2661-2666(Online) International Scientific Journal Monte (ISJM) DOI: 10.33807/monte.202004731 No. 2 (2020): April
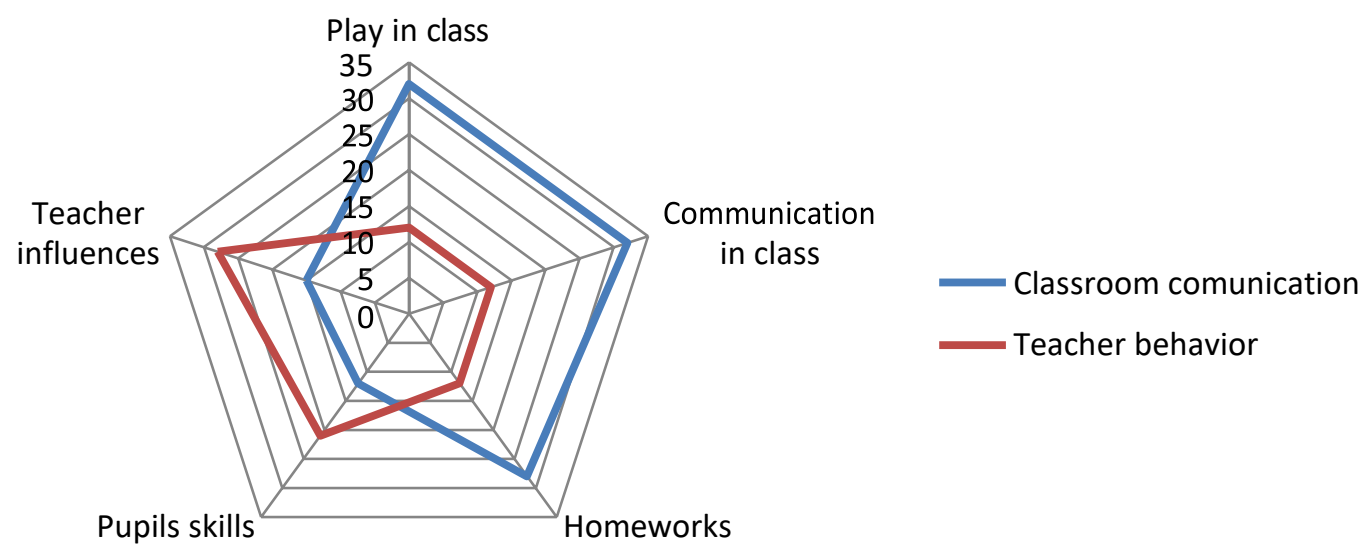

\section{LITERATURE AND REVIEW}

a) A middle school girl experiences bullying from other students and approaches her social studies teacher to discuss it because she trusts that the teacher will listen and help without making her feel socially inept.

b) Positive teacher-student relationships contribute to school adjustment and academic and social performance

c) These findings were greater for boys than for girls (Hamre \& Pianta, 2001).

d) Further work indicates that kindergarten children with more closeness and less conflict with teachers developed better social skills as they approached the middle school

How to develop positive relationships with your students;

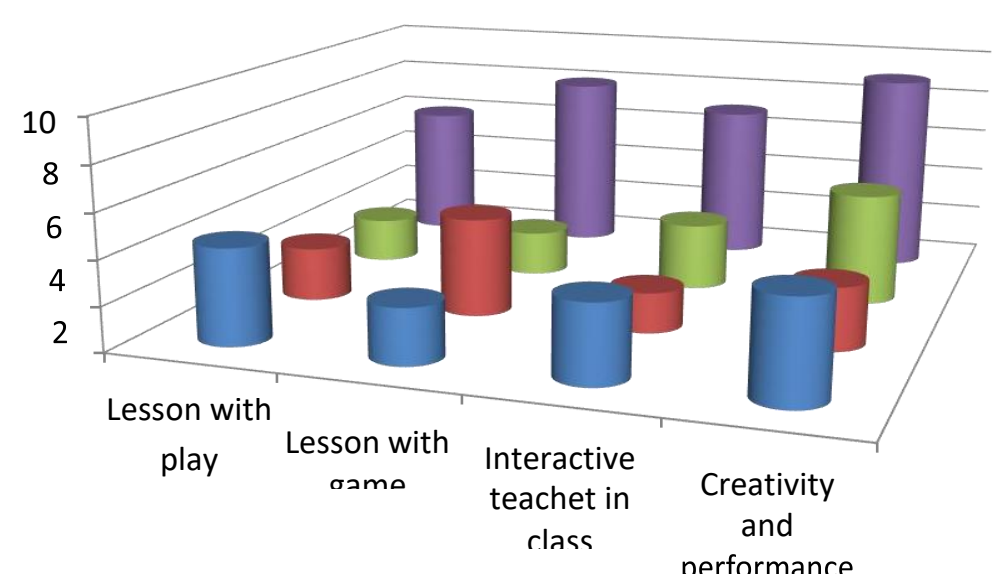




\section{Literature Review and Hypothesis}

The vision of science education described by the standards requires changes throughout the entire system.

Dividing science teaching into separate components oversimplifies a complex process; nevertheless, some division is required to manage the presentation of criteria for good science teaching, accepting that this leaves some overlap. In addition, the teaching standards cannot possibly address all the understanding and abilities that masterful teachers display. Therefore, the teaching standards focus on the qualities that are most closely associated with science teaching and with the vision of science education described in the Standards.

The teaching standards begin with a focus on the long-term planning that teachers do. The discussion then moves to facilitating learning, assessment, and the classroom environment. Finally, the teaching standards address the teacher's role in the school community. The standards are applicable at all grade levels, but the teaching at different grade levels will be different to reflect the capabilities and interests of students at different ages.

The educational system must act to sustain effective teaching. The routines, rewards, structures, and expectations of the system must endorse the vision of science teaching portrayed by the Standards. Teachers must be provided with resources, time, and opportunities to make change as described in the program and system standards. They must work within a framework that encourages their efforts.

The changes required in the educational system to support quality science teaching are major ones. Each component of the system will change at a different pace, and most changes will be incremental. Nonetheless, changes in teaching must begin before all of the systemic problems are solved. Source: Science Teaching Standards 2008

Motivation is closely linked to student's perceptions of teacher expectations. Studies of middle and high school students have shown that students shape their own educational expectations from their perceptions of their teachers' expectations (Muller, Katz, \& Dance, 1999). Students who perceive that their teachers have high expectations of their academic achievement are more motivated to try to meet those expectations and perform better academically than their peers who perceive low expectations from their teachers (Muller et al., 1999).

Due to the influence of expectations on motivation, expectations can be an important factor on a students' academic achievement. Although there is more research regarding the academic effects of positive teacher-student relationships for older students, there are notable social outcomes as well. Teachers are an important source of social capital for students (Muller, 2001). Social capital in a classroom setting is defined as caring teacher-student relationships where students feel.

\section{Conclusion}

In future, it is expected that infectious diseases will be more dangerous than ever; and in this regard, a trend of future problems and go to meet them on preemptive basis, should be adapted to this situation. In this sense, the introduction of essential in the overall Republic of Albania security system, and the school population and school must be a priority to be protected against outbreaks of infectious diseases.

Over the years, educators have developed many teachings and learning models relevant to classroom science teaching. Knowing the strengths and weaknesses of these models, teachers examine the relationship between the science content and how that content is to be taught. Teachers of science integrate a sound model of teaching and learning, a practical structure for the sequence of activities, and the content to be learned.

Inquiry into authentic questions generated from student experiences is the central strategy for teaching science. Teachers focus inquiry predominantly on real phenomena, in classrooms, outdoors, or in laboratory settings, where students are given investigations or guided toward fashioning investigations that are demanding but within their capabilities.

Actions of teachers are deeply influenced by their understanding of and relationships with students.

1. The standards for science teaching require building strong, sustained relationships with students.

2. These relationships are grounded in knowledge and awareness of the similarities and differences in students' backgrounds, experiences, and current views of science.

3. The diversity of today's student population and the commitment to science education for all requires a firm belief that all students can learn science.

4. These differences include integration vs. separation of cognition and affect, heavily normative vs. goalreferenced evaluation of competence, aggregated vs. context-specific judgment, hierarchical vs. loosely hierarchical structure, past vs. future orientation, and relative temporal stability vs. malleability.

Empirical evidence does show that teacher-student relationships are very important for high school students Due to the ever-changing nature of the American educational system and the increasingly diverse student body, more current studies are needed to look at the effects of teacher-student relationships for this changing population. It is important to learn more about teacher-student relationships for low-income students to decrease high school dropout, and improve students' social-emotional development. 


\section{REFERENCES AND BOOKS}

Ainsworth, M. D. S. (1982). Attachment: Retrospect and prospect. In C.M. Parkes \& J. Stevenson-Hinde (Eds.), The place of attachment in human behavior (pp. 3-30). New York: Basic Books.

Alexander, K. L Entwisle, D. R., \& Horsey, C. S. (1997). From first grade forward: "Early foundations of high school dropout». Sociology of Education" 87-107.

Baker, J. Grant \& Morlock, L (2008). The teacher-student relationship as a developmental context for children with internalizing or externalizing behavior problems

Cataldi, E. F., Laird, J. \& Kewalramani, A. (2009). High school dropout and completion rates in the United States: 2007 (NCES 2009-064). Washington, DC: National Center for Education Statistics, Institute of Education Sciences,

U.S. Department of Education.

Orth, U., Robins, R. W., \& Widaman, K. F. (2012) "Life-span development of self-esteem and its effects on important life outcomes".Journal of personality and social psychology, 102(6), 1271.

McCormick, M., O’Connor, E.E., Cappella, E. \& McClowry, S. (Accepted). Teacher-child relationships and academic achievement: A multi-level propensity score model approach. "Journal of School Psychology" Disaster Risk Reduction in Education in Emergencies, UNICEF, save the children, 2010.

Hargreaves J. R, Glynn J, Educational attainment and HIV infection in developing countries: a re-view of the published literature, London, Infectious Disease Epidemiology Unit, Department of Infectious and Tropical Diseases, London School of Hygiene and Tropical Medicine, 2000.

Kekić, Dalibor, Security management system during an outbreak of acute infectious diseases, Faculty of Security Studies, Belgrade, 2010.

Management of Chronic Infectious Diseases in Schoolchildren, Illinois State Board of Education, Illinois, Revised Edition, 2003. 